\title{
MEDICAL DOCTORS IN HUNGARY: 30 YEARS AFTER GRADUATION \\ DATA ON LIFESTYLE, MORBIDITY, DEMOGRAPHY AND DIFFERENCES BETWEEN SPECIALTIES
}

\author{
Imre Rurik ${ }^{1}$, Endre Szigethy², Zoltán Langmár ${ }^{3}$ \\ 1Department of Family and Occupational Medicine, Faculty of Public Health, University of Debrecen, Debrecen, Hungary \\ ${ }^{2}$ Epidemiological Research Group of the Hungarian Academy of Science, Department of Preventive Medicine, Faculty of Public Health, Univer- \\ sity of Debrecen, Debrecen, Hungary \\ ${ }^{3}$ Second Department of Obstetrics and Gynaecology, University of Semmelweis, Budapest, Hungary
}

\begin{abstract}
SUMMARY
There are few studies from East and Central European countries on health-status, lifestyle and social circumstances of medical professionals. We evaluated data of a cohort of physicians who had graduated 30 years ago in Hungary and compared the data of their professional carrier, life style, health outcomes, and medical specialties.

Questionnaires compiled by an expert group and filled in by 208 physicians (83 men and 125 women) were analysed. Men mostly work as surgeons, women were mostly employed as primary care specialists. Women changed their specialty and/or place of work more often than men. Male primary care physicians had more children than women and others specialists. At graduation, most of them had a normal BMI. Since then, a significant increase in weight and BMI was observed in both genders and across all specialty groups. The largest increase in body weight and BMI (mean 5.27) was recorded among female primary care physicians. Recorded physical activity was low in general, with male primary care specialists being most active and female primary care physicians the least. Female doctors in surgical specialties had longer resting time. Male physicians rarely participated in regular health screenings. The incidence of hypertension was higher than the Hungarian national average for that age. About $5 \%$ of primary care physicians identified themselves as regular smokers. Abstinence and regular daily alcohol consumption were reported in equal ratio. Burn-out symptoms were rarely experienced.

This generation had started its medical profession before the significant progressive changes in the medicine occurred in the last decades. While physicians do not always follow their own professional advices, their lifestyle proved a little bit healthier than that of the population at large, especially for women and their health outcomes, except hypertension, were also better. In general, they were not satisfied with the financial and working conditions of the recent Hungarian healthcare system.
\end{abstract}

Key words: demography, doctors, health, family physicians, lifestyle, morbidity, primary care, Hungary

Address for correspondence: I. Rurik, Department of Family and Occupational Medicine, Faculty of Public Health, University of Debrecen, Móricz Zs.krt.22, 4032 Debrecen, Hungary. E-mail: Rurik.dr@t-online.hu

\section{INTRODUCTION}

The mental well-being and physical fitness of medical doctors represent an important issue for health services worldwide $(1,2)$. Some studies focused only on female physicians, while others surveyed recent medical graduates $(3,4)$. General practitioners (GPs) represent the largest group of physicians (4). Other studies focused on specific issues such as smoking (in France, Greece, Switzerland, and Poland) or alcohol consumption (in Estonia, Hungary, Germany, USA, and India) (5-11).

Mental health problems, particularly depression due to overwork and emotional pressure, are severe $(12,13)$. Indeed, work satisfaction is known to be negative predictor of mental disorders, especially among women (14).

Doctors often fail to follow the same current preventive health recommendations they advice their patients. Moreover, research suggests that a large proportion of doctors have never registered with a general practitioner (15).
Quality of life is linked to a number of factors, to profession and working position (16).

Studies focused mainly on psychological health, thus information concerning the physical health and relation to social circumstances remains limited. No previous study evaluating these differences between medical specialties was found.

We aimed to evaluate the morbidity, demographic characteristics and lifestyle factors prevailing in the study cohort of Hungarian physicians and compare the data to those of the general population.

\section{MATERIALS AND METHODS}

\section{Subjects}

The subjects were recruited from 423 physicians who graduated in 1979 at Semmelweis University of Medicine, Budapest, 
Hungary. Hundred and thirty-eight doctors who participated at the 30 -year jubilee meeting (November 2009) were asked to complete a questionnaire. It was also sent to 88 colleagues who were not present but their addresses were available.

\section{Survey Design}

The questionnaire consisted of 42 multiple-choice questions and 11 sub-questions, in the following sections:

- demographic data: gender, age, marital status, number of children, and place of residence;

- medical career: pre- and post-graduation intentions, the number of years spent in different fields of medicine; place and position of their job; their overall job satisfaction;

- anthropometric data: current and 1979 height and weight;

- morbidity data;

- self-reported health: rating own health status, comparison to patients of the same age, and participation in routine screening;

- lifestyle factors: physical activity and leisure time activities, sleeping, smoking habit, and alcohol consumption.

They were inquired about the recent problems of the Hungarian healthcare system.

In some questions, there were overlaps between answers and there are lacking data in others, therefore numbers and percentages are often not identical.

\section{Statistical Analysis}

Continuous variables were compared using Student's unpaired t-test or ANOVA. Categorical variables were evaluated using a $\chi^{2}$ or Fisher's test, as appropriate.

\section{RESULTS}

208 questionnaires (83 men and 125 women) were accepted and analyzed.

\section{Demographic Findings}

The mean age $( \pm \mathrm{SD})$ of participants was $55.2 \pm 2.1$ (range: 54-67 years) with an average of $2.20 \pm 1.09$ children for males and $1.87 \pm 1.03$ children for females. Male primary care physicians have more children $(2.43 \pm 0.82)$ than women $(1.87 \pm 0.93)$; however, there was no significant difference between specialties $(p=0.34)$. Ninety percent of men and $73 \%$ of women were married, $6 \%$ and $15 \%$ divorced, respectively. Of all the women $3 \%$ lived with their spouse and $8 \%$ were widowed.

The geographic distribution of place of residence and employment is presented in Table 1.

Among those who had previously left Hungary, most immigrated to America or Western European countries.

Table 1. Distribution according to the place of work or residency and gender (some respondents gave multiple answers)

\begin{tabular}{|c|c|c|c|c|c|c|}
\hline \multirow{3}{*}{ Place of work or residency } & \multicolumn{3}{|c|}{$\operatorname{Men}(\mathrm{N}=83)$} & \multicolumn{3}{|c|}{ Women $(\mathrm{N}=125)$} \\
\hline & \multirow[b]{2}{*}{$n(\%)$} & \multicolumn{2}{|c|}{ duration of employment (years) } & \multirow[b]{2}{*}{$\mathrm{n}(\%)$} & \multicolumn{2}{|c|}{ duration of employment (years) } \\
\hline & & mean & SD & & mean & SD \\
\hline Budapest & $50(60)$ & 21.1 & 8.5 & $71(50)$ & 23.6 & 9.2 \\
\hline Big city & $10(12)$ & 15.8 & 12 & $16(11)$ & 4.7 & 0.5 \\
\hline Small city & $24(25)$ & 8.8 & 9.2 & $33(24)$ & 11.0 & 6.1 \\
\hline Village & $5(6)$ & 9.3 & 11.9 & $6(5)$ & 14.3 & 6.2 \\
\hline Abroad & $10(12)$ & 11.2 & 10.9 & $6(5)$ & 10.8 & 6.9 \\
\hline
\end{tabular}

Table 2. Specialty groups and years spent in this field (some doctors worked in more specialties)

\begin{tabular}{|l|c|c|c|c|c|c|}
\hline \multirow{2}{*}{ Type of specialty } & \multicolumn{3}{|c|}{ Men (N=83) } & \multicolumn{3}{|c|}{ Women (N=125) } \\
\cline { 2 - 7 } & & time spent in the field (years) & & \multicolumn{2}{|c|}{ time spent in the field (years) } \\
\cline { 2 - 7 } & $\mathbf{n}(\%)$ & mean & SD & $\mathrm{n}(\%)$ & mean & 19.8 \\
\hline $\begin{array}{l}\text { Primary care (family physician, } \\
\text { occupational health) }\end{array}$ & $20(24)$ & 20.2 & 9.4 & $41(33)$ & 10.2 \\
\hline $\begin{array}{l}\text { Non-surgical (internist, psychiatry, } \\
\text { neurology, podiatry, etc.) }\end{array}$ & $21(27)$ & 21.4 & 10.3 & $49(39)$ & 21.8 & 9.6 \\
\hline $\begin{array}{l}\text { Surgical (surgery, urology, ENT, } \\
\text { ophthalmology, etc.) }\end{array}$ & $29(36)$ & 24.3 & 9.6 & $20(13)$ & 18.9 & 11.8 \\
\hline $\begin{array}{l}\text { Oxyology } \\
\text { Anaesthesiology }\end{array}$ & $1(1)$ & 30 & 0 & $7(6)$ & 5.3 & 4.1 \\
\hline Diagnostic (radiology, pathology) & $10(12)$ & 16.4 & 12.8 & $15(13)$ & 22.5 & 11.8 \\
\hline Other (non medical/governmental) & $12(16)$ & 18.6 & 9.3 & 13 & 14.8 & 11.9 \\
\hline
\end{tabular}




\section{Medical Careers}

Significantly $(\mathrm{p}<0.01)$ more men were specialists in surgery (Table 2). Most of the men working in the specialty had intended to work in this field at the time of graduation, whereas women were more likely to have deviated from their career paths $(p=0.04)$. Since graduation, $30 \%$ of men and $48 \%$ of women changed their working place and/or specialty $(\mathrm{p}<0.05)$, usually based on family $(9 \%$ and $24 \% ; p=0.02)$ or professional reasons $(18 \%$ and $12 \%)$, respectively. However, for both genders career changes were equally likely to be for financial reasons $(5 \%)$ or because of changing place of residence (4\%). Around $10 \%$ of women and $23 \%$ of men had previously worked abroad.

The participants were working in the whole range of healthcare: administrative leaders (including the Minister of Health), ten of them were university professors (in Hungary or abroad). Around $40 \%$ of men and $22 \%$ of women worked in senior positions, $36 \%$ and $41 \%$ as private practitioners, and $25 \%$ and $34 \%$ within the public healthcare system, respectively.

The number of on-call duties (night shifts) decreased by decades from 6-8 monthly in the first decade of carrier to about 2 , thirty years later, mainly due to appointment to a senior position.

\section{Anthropometric Findings}

A significant increase in weight and BMI was observed for both genders and across all specialty groups (Table 3 ).

There was no significant difference between the genders or medical specialties. The largest increase in body weight and BMI (mean: 5.27; 95\% CI 3.84-6.69) was observed among female primary care specialists. At the time of graduation, the majority of the respondents had normal BMI values, whereas at the time of the survey many of them, mostly men, were considered overweight or obese (Table 4).

\section{Morbidity}

Medications were used by $41 \%$ of men and $44 \%$ of women, respondents on regular medication mostly live in big cities $(\mathrm{p}=0.041)$. The most frequent diagnoses can be found in Table 5 .

Few of the respondents mentioned psychological morbidities. Of those diagnosed with a lipid disorder, all were living outside of Hungary; women were more likely to use lipid-lowering therapy than men, mainly for secondary prevention. With respect to treatment adherence, $56 \%$ of men and $70 \%$ women always, $38 \%$ and $14 \%$ seldom, and $4 \%$ of both genders never follow medical recommendations, without any difference regarding specialty.

Over the past 30 years, $73 \%$ of men and $77 \%$ of women had received an average of 1.4 hospitalizations (besides delivery). Of the respondents, $46 \%$ reported that as patients, they received preferential treatment from medical personnel.

When treating patients, $28 \%$ of the doctors paid more attention to the patients suffering from the same conditions as the doctors themselves. Only $36 \%$ of the male and $20 \%$ of the female doctors had their own family physicians $(55 \%$ in administrative terms for both genders). Female physicians were significantly less likely to be treated by family physicians than men (in 29\%).

\section{Self-perceived Health Status}

Twelve percent of male and $22 \%$ of female compared their own health status and appearance to that of their patients, and $70 \%$ of men and $64 \%$ of women believed that their health status was better. Almost $21 \%$ of men and $15 \%$ of women believed that their profession had a negative impact on their health status. Of the males, $37 \%$ regularly attended screening examinations or diagnostic procedures in comparison with $57 \%$ of female doctors.

Table 3. Registered anthropometric parameters, recent and 30y ago

\begin{tabular}{|c|c|c|c|c|c|c|c|c|c|c|c|c|}
\hline & \multicolumn{6}{|c|}{ Men $(\mathrm{N}=83)$} & \multicolumn{6}{|c|}{ Women $(\mathrm{N}=125)$} \\
\hline & \multicolumn{2}{|c|}{ height } & \multicolumn{2}{|c|}{ weight } & \multicolumn{2}{|c|}{ BMI } & \multicolumn{2}{|c|}{ height } & \multicolumn{2}{|c|}{ weight } & \multicolumn{2}{|c|}{ BMI } \\
\hline & mean & SD & mean & SD & mean & SD & mean & SD & mean & SD & mean & SD \\
\hline Recent & 178.6 & 7.1 & 88.6 & 15.4 & 27.7 & 4.2 & 164.5 & 6.4 & 68.4 & 11.3 & 24.2 & 3.1 \\
\hline Graduation & & & 77.2 & 11.1 & 25.4 & 4.2 & & & 57.1 & 7.7 & 21.1 & 2.5 \\
\hline
\end{tabular}

Table 4. Moving to higher BMI categories since time of graduation

\begin{tabular}{|c|c|c|c|c|c|c|}
\hline & \multicolumn{2}{|c|}{ Recent BMI } & \multicolumn{4}{|c|}{ BMI at graduation } \\
\hline & & $n$ & $\begin{array}{l}\text { underweight } \\
<18.5 \mathrm{~kg} / \mathrm{m}^{2}\end{array}$ & $\begin{array}{c}\text { normal } \\
18.5-24.9 \mathrm{~kg} / \mathrm{m}^{2}\end{array}$ & $\begin{array}{c}\text { overweight } \\
25-29.9 \mathrm{~kg} / \mathrm{m}^{2}\end{array}$ & $\begin{array}{c}\text { obese } \\
30 \mathrm{~kg} / \mathrm{m}^{2}\end{array}$ \\
\hline \multirow{3}{*}{$\begin{array}{l}\text { Men } \\
N=83\end{array}$} & normal & 23 & 0 & 21 & 2 & 0 \\
\hline & overweight & 35 & 0 & 22 & 13 & 0 \\
\hline & obese & 25 & 0 & 13 & 6 & 6 \\
\hline \multirow{3}{*}{$\begin{array}{l}\text { Women } \\
N=125\end{array}$} & normal & 60 & 2 & 55 & 3 & 0 \\
\hline & overweight & 42 & 6 & 33 & 3 & 0 \\
\hline & obese & 13 & 0 & 11 & 1 & 1 \\
\hline
\end{tabular}


Table 5. The most frequent pathologies, time since diagnosis were set up (means and $\pm S D$ )

\begin{tabular}{|c|c|c|c|c|c|c|}
\hline \multirow[b]{3}{*}{ Diagnoses } & \multicolumn{3}{|c|}{ Men $(\mathrm{N}=83)$} & \multicolumn{3}{|c|}{ Women $(N=125)$} \\
\hline & \multirow[b]{2}{*}{$\mathrm{n}(\%)$} & \multicolumn{2}{|c|}{ time since diagnosis (years) } & \multirow[b]{2}{*}{$\mathrm{n}(\%)$} & \multicolumn{2}{|c|}{ time since diagnosis (years) } \\
\hline & & mean & SD & & mean & SD \\
\hline Diabetes & $5(6)$ & 8 & 5.3 & $2(2)$ & 3 & \\
\hline Hypertension & $27(33)$ & 8.8 & 5.3 & $30(24)$ & 8.7 & 11.8 \\
\hline Lipid disorder & $7(8)$ & 4.8 & 3.4 & $11(9)$ & 8.6 & 15.6 \\
\hline Malignancy & $3(4)$ & 3 & 2.8 & $7(6)$ & 6.3 & 5.0 \\
\hline Rheumatoid disorders & $5(6)$ & 6.2 & 5.6 & $9(7)$ & 9.1 & 7.5 \\
\hline
\end{tabular}

Table 6. Sleeping habit; characteristic and length of daily sleeping

\begin{tabular}{|l|c|c|c|c|c|c|c|c|}
\hline \multirow{2}{*}{} & \multicolumn{4}{|c|}{ Characteristics of sleeping N (\%) } & \multicolumn{4}{c|}{ Length of sleeping (hours) } \\
\cline { 2 - 10 } & \multirow{2}{*}{ quiet } & \multirow{2}{*}{ troubled } & \multicolumn{2}{|c|}{ using sleeping pills } & \multicolumn{2}{c|}{ workdays } & \multicolumn{3}{c|}{ weekends } \\
\cline { 4 - 10 } & & sometimes & always & mean & SD & mean & SD \\
\hline Men & $51(62)$ & $19(24)$ & $4(5)$ & $1(2)$ & 6.6 & 0.92 & 7.7 & 0.9 \\
\hline Women & $81(65)$ & $22(18)$ & $4(3)$ & $4(3)$ & 6.7 & 0.91 & 7.6 & 0.9 \\
\hline
\end{tabular}

\section{Lifestyle Indicators}

Self-reported sleep patterns were generally good, reported to be longer at weekends (both genders) and in all specialist groups (Table 6). Female doctors in surgical specialties reported an average of 7.2 hours of sleep per night between workdays - a significantly longer rest time when compared to other medical specialties $(\mathrm{p}=0.049)$.

\section{Physical Activity}

Twenty two percent of male and $12 \%$ of female reported sport activity on a daily basis, while $15 \%$ and $12 \%$ of women reported no physical activity.

Men were significantly more active than women, although female physicians considered regular exercise to be more important than males. Male primary care physicians performed 4.4 exercise sessions weekly, while female primary care physicians only 1.2 sessions $(p=0.001)$.

\section{Smoking}

Only $5 \%$ of men and $6 \%$ of women were regular smokers at this time. For those who quit smoking, the mean age of quitting was $44.1 \pm 12.1$ years for men and $39.6 \pm 10.6$ years for women.

\section{Alcohol and Substance Abuse}

Based on self-reported data, 9\% of men and $10 \%$ of women abstained from drinking alcohol, while $58 \%$ and $72 \%$ only imbibed occasionally, and $8 \%$ of both genders reported regular drinking. The amount of consumed alcohol was $4.8 \pm 4.1$ units per week for men and $1.65 \pm 0.98$ units per week for women. The mean age when regular drinking commenced was $27.6 \pm 7.9$ years in men and $32.8 \pm 10.4$ years in women. No differences between medical specialties were found, but male surgeons reported higher consumption ( $5.1 \pm 10.6$ unit per week; $p=0.048)$. Substance and narcotic use was not inquired.

\section{Leisure Time}

Women were significantly more likely to read novels $(40 \%$ versus $16 \%)$ while men undertake physical activities $(53 \%$ versus $35 \%$ ).

\section{Burn-out}

Thirty years after graduation, $41 \%$ of male and $37 \%$ of female doctors were content, while $44 \%$ of male and $51 \%$ of female were often satisfied with their profession.

\section{DISCUSSION}

\section{Demography}

Male doctors have more children than females, and the fact that primary care physicians tended to have larger families may reflect the different working conditions between specialties (13, 17). Within the cohort, divorce rates were smaller than in the USA (18). The distribution of medical specialties follows a similar pattern to the overall Hungarian medical community (17). Budapest is geographically over-represented. In Hungary, there is limited mobility between cities and regions.

\section{Medical Careers}

In other countries, general practice was commonly chosen for lifestyle reasons; desire to have close contact with patients and shorter postgraduate training have also been cited as factors motivating graduates to enter primary care positions $(19,20)$. Since primary care was recognised in Hungary as board specialty only 30 years ago, it was not a career option for the respondents.

The major problems affecting healthcare system were rated as a lack of financial resources, followed by human resource constraints. The average age of doctors in Hungary is quite high, for primary care the average age is over 57 years. There is no 
incentive for junior doctors to specialise in primary care due to low salaries. The informal payment (tipping) system used to obtain better access or a higher quality service is still widespread in Hungary and that has a negative effect on the healthcare system.

In the last years, many of experienced doctors have left Hungary in favour of other countries with better work condition and 6-8 times higher salaries.

\section{Anthropometric}

Changes in BMI were expected to match global trends in obesity and are similar to the findings of a study on US physicians of the same age groups (20-22). The higher proportion of weight gain of primary care specialists may be explained by the characteristics of the specialty and by individual lifestyle factors (2).

\section{Morbidity}

The incidence of hypertension among doctors was higher, but lower than in the USA, the prevalence of other illnesses had the same ratio than in the average Hungarian population $(17,20)$.

\section{Self-reported Health Status}

Female physicians were found to be more conscious of their appearance and health status than males. This can be explained by the different gender attitudes. All of the respondents judged their health status to be better than that of the general population, which is similar to another survey (23). Male physicians rarely participate in regular health screens. About one third of the respondents do not have their own local family doctor. This may be because in Hungary, one can access secondary care or tertiary hospitals without attending the family physician, whereas in other countries cannot $(24,25)$.

\section{Lifestyle Indicators}

Females demonstrated better scores for healthy eating, rate of weight gain, and alcohol consumption. The proportion of smokers among physicians was lower than in other countries $(7,11,26)$.

\section{Limitations}

It was impossible to find more persons of this cohort. Data was largely obtained using self-reporting questionnaires, thus the possibility of recall bias cannot be ruled out. Other limitations may include missing data in the findings. The relationship between working conditions and drugs prescribed for medical reasons was not evaluated.

To our knowledge no other study with such a wide range of questions has been published covering this geographical area and from this time period $(27,28)$.

\section{CONCLUSIONS}

Attitudes, orientations, motivations and working circumstances of physicians have changed during the last decades. Working in the medicine field has never been a well-paid job in the Eastern
European countries (27). We believe that members of this cohort have chosen medicine rather a profession than a mere job. Although physicians do not always follow their own professional advices, their lifestyle proved a little bit healthier than that of the population at large, especially in women, i.e., their health outcomes, except hypertension, were better. In general, respondents were not satisfied with the financial and working conditions of the recent Hungarian healthcare system.

\section{Acknowledgement}

Thanks to our departmental secretary Judit Rusznyák for data input, and to Viktória Vértes, Alexandra Kisov, Elisabeth Szecsődi, and Daniel Martin for technical help, and to Maria Martin for corresponding questionnaires.

\section{Authors' Contributions}

IR - constructing questionnaire, corresponding with participants, text writing, literature search, final text editing, ESz - analyzing data, ZL managing questionnaires, literature search, text writing.

\section{Conflict of Interests \\ None declared}

Ethics approval was previously obtained through the regional Ethical Committee (South-Budapest region).

This study did not have any funding; only departmental resources were available.

\section{REFERENCES}

1. Sesso HD, Gaziano JM, VanDenburgh M, Hennekens CH, Glynn RJ, Buring JE. Comparison of baseline characteristics and mortality experience of participants and nonparticipants in a randomized clinical trial: the Physicians' Health Study. Control Clin Trials. 2002 Dec;23(6):686-702.

2. Ajani UA, Lotufo PA, Gaziano JM, Lee IM, Spelsberg A, Buring JE, et al. Body mass index and mortality among US male physicians. Ann Epidemiol. 2004 Nov;14(10):731-9.

3. McMurray JE, Linzer M, Konrad TR, Douglas J, Shugerman R, Nelson K; The SGIM Career Satisfaction Study Group. The work lives of women physicians: results from the Physician Work Life Study. J Gen Intern Med. 2000 Jun;15(6):372-80.

4. Evans J, Lambert T, Goldacre M. GP recruitment and retention: a qualitative analysis of doctors' comments about training for and working in general practice. Occas Pap R Coll Gen Pract. 2002 Feb;(83):iii-vi, 1-33.

5. Innos K, Rahu K, Baburin A, Rahu M. Cancer incidence and causespecific mortality in male and female physicians: a cohort study in Estonia. Scand J Public Health. 2002;30(2):133-40.

6. Sebo P, Bouvier Gallacchi M, Goehring C, Künzi B, Bovier PA. Use of tobacco and alcohol by Swiss primary care physicians: a cross-sectional survey. BMC Public Health. 2007 Jan 12;7:5.

7. Josseran L, King G, Guilbert P, Davis J, Brücker G. Smoking by French general practitioners: behaviour, attitudes and practice. Eur J Public Health. 2005 Feb;15(1):33-8.

8. Wunsch MJ, Knisely JS, Cropsey KL, Campbell ED, Schnoll SH. Women physicians and addiction. J Addict Dis. 2007;26(2):35-43.

9. Kumar P, Basu D. Substance abuse by medical students and doctors. J Indian Med Assoc. 2000 Aug;98(8):447-52.

10. Sotiropoulos A, Gikas A, Spanou E, Dimitrelos D, Karakostas F, Skliros E, et al. Smoking habits and associated factors among Greek physicians. Public Health. 2007 May;121(5):333-40.

11. Ostrowska A, Szewczyńiski JA. The assessment of health behaviours among Warsaw Medical University students. Wiad Lek. 2002;55 Suppl 1(Pt 2):831-5. (In Polish.)

12. Tyssen R, Vaglum P. Mental health problems among young doctors: an updated review of prospective studies. Harv Rev Psychiatry. 2002 MayJun;10(3):154-65. 
13. Ádám S, Györffy Z, Harmatta J, Túry F, Kopp M, Szényei G. Psychiatric and somatic morbidity among Hungarian psychiatrists. Psychiatr Hung. 2010;25(1):55-61. (In Hungarian.)

14. Noriega M, Gutiérrez G, Méndez I, Pulido M. Female health workers: lifestyle, work, and psychiatric disorders. Cad Saude Publica. 2004 SepOct;20(5):1361-72. (In Spanish.)

15. Kay MP, Mitchell GK, Del Mar CB. Doctors do not adequately look after their own physical health. Med J Aust. 2004 Oct 4;181(7):368-70.

16. Jurkat HB. Quality of life for physicians and women physicians. Experiences from empirical research. Dtsch Med Wochenschr. 2008 Jan;133(12):14-6. (In German.)

17. Yearbook of health statistics, 2011. Budapest: Hungarian Central Statistical Office; 2012.

18. Harms BA, Heise CP, Gould JC, Starling JR. A 25-year single institution analysis of health, practice, and fate of general surgeons. Ann Surg. 2005 Oct;242(4):520-6; discussion 526-9.

19. Mobilos S, Chan M, Brown JB. Women in medicine: the challenge of finding balance. Can Fam Physician. 2008 Sep;54(9):1285-1286.e5.

20. Scott I, Gowans M, Wright B, Brenneis F, Banner S, Boone J. Determinants of choosing a career in family medicine. CMAJ. 2011 Jan 11;183(1):E1-8.

21. Borges NJ, Hartung PJ. Stability of values during medical school. Med Teach. 2010;32(9):779-81.

22. Creed PA, Searle J, Rogers ME. Medical specialty prestige and lifestyle preferences for medical students. Soc Sci Med. 2010 Sep;71(6):1084-8.

23. Thompson WT, Cupples ME, Sibbett CH, Skan DI, Bradley T. Challenge of culture, conscience, and contract to general practitioners' care of their own health: qualitative study. BMJ. 2001 Sep 29;323(7315):728-31.
24. Hummers-Pradier E, Beyer M, Chevallier P, Eilat-Tsanani S, Lionis C, Peremans L, et al. Research agenda for general practice/family medicine and primary health care in Europe. Maastricht: European General Practice Research Network; 2009.

25. Szabó KJ, Ádány R, Balla J, Balogh Z, Boda Z, Édes I, et al. Advances in the prevention, diagnosis and therapy of vascular diseases. Orv Hetil. 2012 Apr 1;153(13):483-98. (In Hungarian.)

26. Buddeberg-Fischer B, Stamm M. The medical profession and young physicians' lifestyles in flux: challenges for specialty training and health care delivery systems. Swiss Med Wkly. 2010 Dec 7;140:w13134. doi: 10.4414/smw.2010.13134.

27. Oleszczyk M, Švab I, Seifert B, Krzton-Królewiecka A, Windak A. Family medicine in post-communist Europe needs a boost. Exploring the position of family medicine in healthcare systems of Central and Eastern Europe and Russia. BMC Fam Pract. 2012 Mar 12;13:15. doi: 10.1186/1471-2296-13-15.

28. Tomasik T, Windak A, Seifert B, Kersnik J, Palka M, Margas G, et al. The self-perceived role of general practitioners in care of patients with cardiovascular diseases. A survey in Central and Eastern European countries following health care reforms. Int J Cardiol. 2013 Apr 15;164(3):327-33.

Received April 7, 2013 Accepted in revised form August 8, 2014 